\title{
Comparison between Score for Neonatal Acute Physiology-Perinatal Extension II (SNAP-PE II) and Clinical Risk Index for Babies (CRIB) in Prediction of Neonatal Mortality in Neonatal Intensive Care Unit (NICU) of Tanta University Hospital
}

\author{
MARWA K.T. KHALLAF, M.Sc.*; HEBA S. EL-MAHDY, M.D.*; NIHAL S. SHIHAB, M.D.** and \\ RASHA M.G. EL-SHAFIEY, M.D.* \\ The Departments of Pediatrics* and Public Health \& Community**, Faculty of Medicine, Tanta University, Egypt
}

\begin{abstract}
Background: Survival of the newborns who are admitted to the NICUs do not depend exclusively on birth weight and gestational age, but also on other perinatal factors and physiological conditions of the individual infants, in particular severity of their disease. More than one decade ago, the score for the neonatal acute physiology (SNAP), later the SNAPperinatal extension (SNAP-PE) scores and clinical risk index for babies (CRIB) scores were proposed to be used in assessing severity, with sufficient precision to allow their application for quality assessment.

Aim of Study: Was to compare between two neonatal mortality risk scores, SNAP-PE II and CRIB, in predicting the neonatal mortality in NICU of Tanta University Hospital (TUH ) over a period of one year and to measure the incidence of neonatal deaths in NICU of TUH over a period of one year.

Patients and Methods: This was a prospective cohort study which was carried out on 500 newborns admitted to NICU of TUH over 1 year period. (From February 2016 to February 2017). All neonates were followed-up in NICU till their death or discharge. Neonates who had one of the following criteria were excluded: Newborn who died or was discharged in less than 24 hours after admission to our NICU, Infants whose APGAR score was not known, those who were admitted for observational purposes and those with were inevitably lethal congenital malformations. SNAP-PE II and CRIB scores applied to all the neonates in this study during the first 12 hours after their admission to NICU.
\end{abstract}

Results: Area under the curve of both scores was nearly similar, meaning accuracy of both of them in predicting neonatal mortality.

Conclusion: Both SNAP-PE II and CRIB scores have good sensitivity for predicting neonatal mortality which was slightly higher in SNAP-PE II score.

Key Words: SNAP-PE II score-CRIB score-Neonatal mortality.

Correspondence to: Dr. Marwa K.T. Khallaf, E-Mail: drmarwakhallaf@yahoo.com

\section{Introduction}

SURVIVAL of the newborns who are admitted to the NICUs do not depend exclusively on birth weight and gestational age, but also on other perinatal factors and physiological conditions of the individual infants, in particular severity of their disease [1]. More than one decade ago, the score for the neonatal acute physiology (SNAP), later the SNAP-perinatal extension (SNAP-PE) scores and clinical risk index for babies (CRIB) scores were proposed to be used in assessing severity, with sufficient precision to allow their application for quality assessment [2] . These scores were validated and re-applied in distinct studies in different countries. SNAP assesses the worst clinical status found in the first 24 hours after admission using points assigned to 26 physiological variables: The higher the score, the greaterthe risk of death. With the Score for Neonatal Acute Physiology Perinatal Extension (SNAP-PE), 3 additional variables were added: Birth weight, the Apgar score, and being small for gestational age [3]. Due to the time needed to complete scoring, the authors subsequently developed a simplified version of the score, using only 5 variables to be measured within 12 hours of admission. The simplified scoring system was designated SNAP II and its perinatal extension SNAP-PE II. These scoring systems have been validated in studies with large numbers of patients and have been shown to be good predictors of mortality in newborns in neonatal intensive care units (NICU) [4] . The CRIB score was created to predict mortality for infants depending on birth weight, gestation, congenital malformation, maximum base deficit in first 12 hours, minimum appropriate Fio 2 in the first 12 hours and maximum appropriate Fio2 in the first 12 hours [5]. 


\section{Patients and Methods}

This was a prospective cohort study. This study was carried out on 500 newborns admitted to NICU of TUH over 1 year period. (From February 2016 to February 2017). All neonates were followed-up in the unit till their death or discharge. The neonates who had one of the following criteria were excluded: Newborn who died or was discharged in less than 24 hours after admission to our NICU, Infants whose APGAR score was not known, those who were admitted for observational purposes and those with inevitably lethal congenital malformations. History taking and clinical examination were done on admission and data was collected from each case including the following: Gestational age assessment on the basis of the date of the last menstrual period and new Ballard score [6], accordingly cases were divided into 4 groups (less than 30 weeks, 30-34 weeks, 35-37 weeks and more than 37 weeks), Sex (male or female), Birth weight was obtained by electronic scale and grouped as follows: (less than 1500 grams, 1500-1999 grams, 20002499 grams and 2500 grams or more), APGAR score at 1 and 5 minutes, Previous incubation, Referral center (the hospital itself and other hospitals), Initial diagnosis (respiratory, cardiac, hematological, infectious, surgical, metabolic, neurological and miscellaneous), and final diagnosis (the same as primary diagnosis). The SNAPII-PE score was calculated on the basis of the following clinical data: Mean blood pressure, temperature, reports of blood gas analysis for $\mathrm{PaO} 2 \&$ serum $\mathrm{PH}$ using arterial samples, urine output, presence of seizures or not, birth weight was recorded for each baby as soon as they arrived in the nursery or NICU for admission, small for gestational age or not and APGAR score was calculated at $1 \mathrm{~min}$. and $5 \mathrm{~min}$. Final score was computed as arithmetic sum of points assigned to each item and after the SNAPII PE score was calculated we divided the cases into 5 groups: 0-9 points, $10-19$ points, $20-29$ points, $30-39$ points and $\geq 40$ points as in Table (1).

CRIB score was calculated on the basis of the following clinical data: Birth weight, gestational age, the maximum values of $\mathrm{FiO} 2$ and the highest value of $\mathrm{BE}$ obtained by arterial blood gas analysis. Each CRIB score variable has a predetermined numerical value that varies according to severity Once the total value of these items was defined, the patients were classified into four levels: Level 1 for scores from 0 to 5 , level 2 from 6 to 10 , level 3 from 11 to 15 and level 4 for scores higher than 15 as in Table (2).

\section{Statistical analysis:}

Statistical analysis of the present study was conducted using the software of the Statistical Package for Social Sciences, SPSS Inc. Chicago, IL, USA, version 21. Qualitative data was summarized in numbers and percentage while quantitative data was summarized in mean and standard deviation for parametric variables. Chi square test or exact tests (Fisher's or Monte Carlo exact test) were applied to test the association between two categorical variables. Relative risk was calculated to estimate the risk of newborn deaths when both the SNAPII and CRIB scores were above the best cut off points (detected by the ROC curve). Multinomial logistic regression was applied to evaluate predictors for neonatal mortality in the SNAPII and CRIB scales. The level of significance was adopted at the $5 \%$ and the significance threshold ( $p$-value) was set at 0.05 . The researcher used Receiver Operating Characteristic (ROC) curve for estimating the sensitivity of both the SNAPII and CRIB scores in prediction of the neonatal mortality.

Table (1): Score for neonatal acute physiology perinatal extension (SNAPII-PE) scoring system [7].

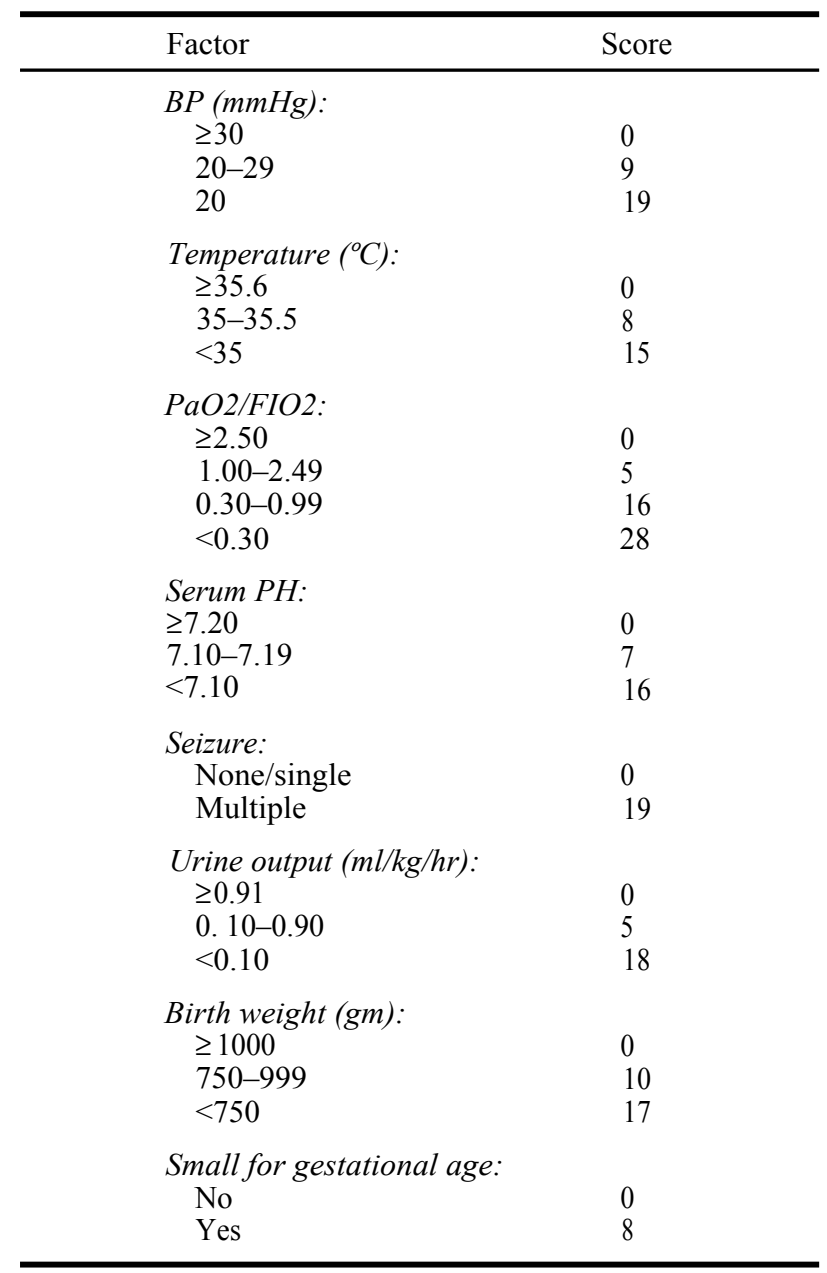


Table (1): Cont.

\begin{tabular}{ll}
\hline Factor & Score \\
\hline Apgar score at 5 minutes: & \\
$7-10$ & 0 \\
$<7$ & 18 \\
\hline Total score: & \\
Group 1 & $0-9$ \\
Group 2 & $10-19$ \\
Group 3 & $20-29$ \\
Group 4 & $30-39$ \\
Group 5 & $\geq 40$ \\
\hline
\end{tabular}

Table (2): Clinical risk index for babies (crib) [8].

\begin{tabular}{lc}
\hline Factor & Score \\
\hline Birhweight $(\mathrm{g})$ : & \\
$>1350$ & 0 \\
$851-1350$ & 1 \\
$701-850$ & 4 \\
$\leq 700$ & 7 \\
Getational age $($ Wk): & \\
$>24$ & 0 \\
$\leq 24$ & 1 \\
Congenital malformation: & \\
None & 0 \\
Not acutely life threatening & 1 \\
Acutely life threatening & 3 \\
Maximum base excess in first $12 \mathrm{~h}:$ & \\
$>-7$ & 0 \\
-7 to -9.9 & 1 \\
-10 to 14.9 & 2 \\
$\geq 15$ & 4 \\
Minimum appropriate fio 2 in the first $12 \mathrm{~h}:$ & \\
$<0.40$ & 0 \\
$0.41-0.80$ & 2 \\
$0.81-0.90$ & 3 \\
$0.91-1.00$ & 4 \\
Maximum appropriate fio2 in the first $12 \mathrm{~h}:$ & \\
$<0.40$ & 0 \\
$0.41-0.80$ & 1 \\
$0.81-0.90$ & 3 \\
$0.91-1.00$ & 5 \\
\hline
\end{tabular}

\section{Results}

Records and data of all patients were collected prospectively. The data of the patients were statistically analyzed and the results are summarized and tabulated in the following tables and figures. 200 cases representing $(40 \%)$ were female and 300 cases representing (60\%) were male as in Fig. (1).

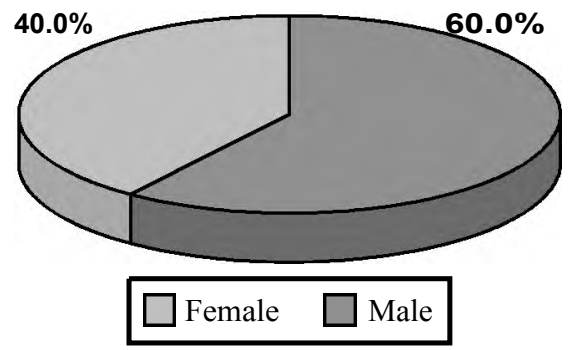

Fig. (1): Sex distribution in this study.
Regarding the gestational age groups, there were about $(7.2 \%)$ included in this study $<30$ weeks, $(25.8 \%)$ from $30-34$ weeks, $(33 \%)$ from $35-37$ weeks and (34\%) $>37$ weeks as in Fig. (2). Gestational age of the cases ranged from 26wk to 40 wk with mean \pm SD $(35.39 \pm 3.15 w k)$.

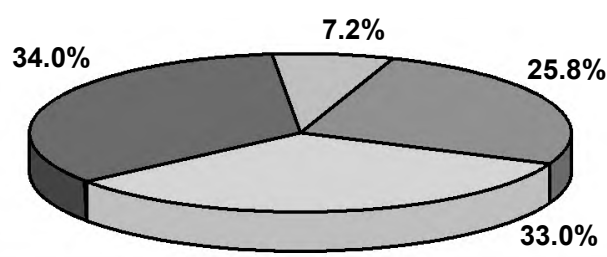

$$
\text { <30wk } \square 30-34 w k \square 35-37 w k \quad \square>37 w k
$$

Fig. (2): Distribution of the neonates according to their gestational age groups

Regarding birth weight of the cases included in this study, there were about (14.6\%) of the cases $<1500 \mathrm{gm},(16.4 \%)$ from 1500-1999gm, (14\%) from 2000-2499 gm and (55\%) $\geq 2500$ gm as in Fig. (3).

Birth weight of the cases ranged from $0.620 \mathrm{~kg}$ to $5.500 \mathrm{~kg}$ with mean $\pm \mathrm{SD}(2.420 \pm 0.830 \mathrm{~kg})$.

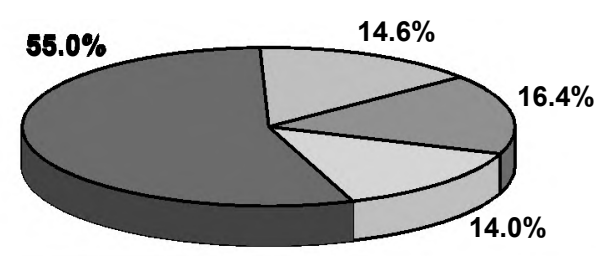

$$
\text { <1500gm } \square \text { 1500-1999 } \square 2000-2499 \square \geq 2500 \text { gm }
$$

Fig. (3): Distribution of the neonates according to their birth weights.

Regarding the initial diagnosis of the cases included in the study is shown as in Fig. (4) about: (80.4\%) Respiratory, (1.8\%) Cardiac, $(2.6 \%) \mathrm{He}-$ matological, (2\%) Surgical, (5\%) Neurological and $(8.2 \%)$ Miscellanous cases.

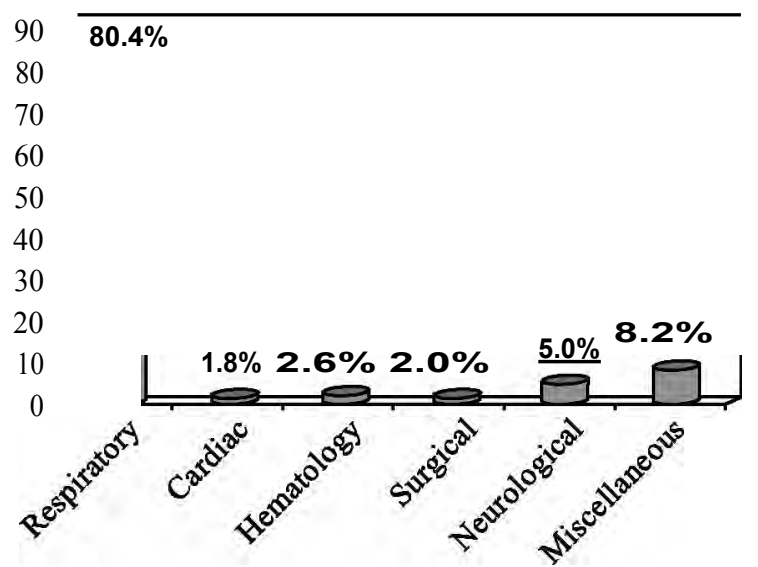

Fig. (4): Distribution of the neonates according to their initial diagnosis. 
As regard incidence of the neonatal deaths in our NICU, about $(74.8 \%)$ of the cases were discharged and (25.2\%) died as shown in Fig. (5).

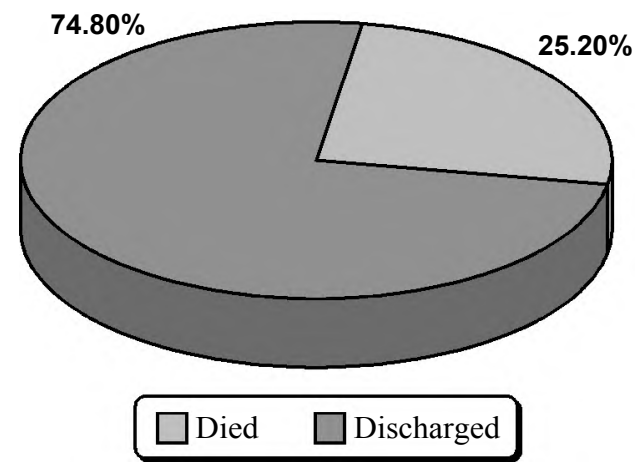

Fig. (5): Incidence of the neonatal deaths in the hospital NICU during a one year.

As regards SNAP-PEII groups in relation to outcome of the studied patients were proved to be statistically significant ( $p$-value $=0.005$ ) Table (3) showed that as the groups increased in severity from group (1) to (5) the neonatal mortality increased $(7.2 \%, 21.5 \%, 48.7 \%, 78.3 \%$ and $85.2 \%)$ respectively.

Table (3): Relationship between SNAP-PE II scores and outcome of newborns admitted to NICU.

\begin{tabular}{|c|c|c|c|c|c|}
\hline \multirow{2}{*}{$\begin{array}{l}\text { Groups of } \\
\text { SNAP-PE II }\end{array}$} & \multicolumn{2}{|c|}{ Outcome } & \multirow{2}{*}{ Total } & \multirow{2}{*}{$\begin{array}{l}\text { Chi } \\
\text { square } \\
\text { test }\end{array}$} & \multirow{2}{*}{$\begin{array}{c}p- \\
\text { value }\end{array}$} \\
\hline & Discharge & Died & & & \\
\hline \multicolumn{6}{|l|}{$\begin{array}{l}\text { SNAP-PE II } \\
\text { score groups: }\end{array}$} \\
\hline \multirow[t]{2}{*}{$0-9$} & 257 & 20 & 277 & & \\
\hline & $92.8 \%$ & $7.2 \%$ & $100.0 \%$ & & \\
\hline \multirow[t]{2}{*}{ 10-19 } & 84 & 23 & 107 & & \\
\hline & $78.5 \%$ & $21.5 \%$ & $100.0 \%$ & & \\
\hline \multirow[t]{2}{*}{$20-29$} & 20 & 19 & 39 & 197.16 & $0.005^{*}$ \\
\hline & $51.3 \%$ & $48.7 \%$ & $100.0 \%$ & & \\
\hline \multirow[t]{2}{*}{$30-39$} & 5 & 18 & 23 & & \\
\hline & $21.7 \%$ & $78.3 \%$ & $100.0 \%$ & & \\
\hline$=$ or more & 8 & 46 & 54 & & \\
\hline than 40 & $14.8 \%$ & $85.2 \%$ & $100.0 \%$ & & \\
\hline
\end{tabular}

As regards CRIB groups in relation to outcome of the studied patients were proved to be statistically significant $(p$-value $=0.005)$ (Table 4$)$ showed that as the groups increased in severity from group (1) to (4) the neonatal mortality increased $(13.9 \%$, $82.9 \%, 90.9 \%$ and $100 \%$ ) respectively.
Table (4): Relationship between CRIB scores and outcome of newborns admitted to NICU.

\begin{tabular}{|c|c|c|c|c|c|}
\hline \multirow{2}{*}{$\begin{array}{l}\text { CRIB } \\
\text { score groups }\end{array}$} & \multicolumn{2}{|c|}{ Outcome } & \multirow{2}{*}{ Total } & \multirow{2}{*}{$\begin{array}{l}\text { Chi } \\
\text { square } \\
\text { test }\end{array}$} & \multirow{2}{*}{$\begin{array}{c}p- \\
\text { value }\end{array}$} \\
\hline & Discharg & Died & & & \\
\hline $\begin{array}{l}\text { CRIB groups: } \\
0-5\end{array}$ & $\begin{array}{l}365 \\
86.1 \%\end{array}$ & $\begin{array}{l}59 \\
13.9 \%\end{array}$ & $\begin{array}{l}424 \\
100.0 \%\end{array}$ & & \\
\hline $6-10$ & $\begin{array}{l}6 \\
17.1 \%\end{array}$ & $\begin{array}{l}29 \\
82.9 \%\end{array}$ & $\begin{array}{l}35 \\
100.0 \%\end{array}$ & & \\
\hline $11-15$ & $\begin{array}{l}3 \\
9.1 \%\end{array}$ & $\begin{array}{l}30 \\
90.9 \%\end{array}$ & $\begin{array}{l}33 \\
100.0 \%\end{array}$ & 189.7 & $0.005^{*}$ \\
\hline More than 15 & $\begin{array}{l}0 \\
0.0 \%\end{array}$ & $\begin{array}{l}8 \\
100.0 \%\end{array}$ & $\begin{array}{l}8 \\
100.0 \%\end{array}$ & & \\
\hline
\end{tabular}

The ROC curve shown in Fig. (6) represents the trade off between sensitivity and specificity for both the SNAP-PE II and CRIB scores. The closer the ROC plot is to the upper left corner, the more accurate would be the test. Both curves for both scores shown in this figure were close to each other with slight differences all over the different cutoff points. They were close to the upper left corner assuming a good degree of accuracy.

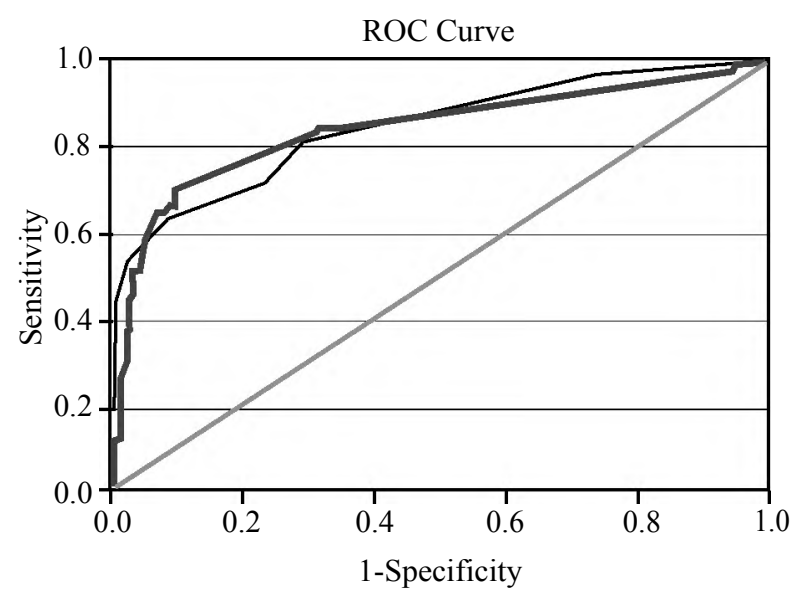

Diagonal segments are produced by ties

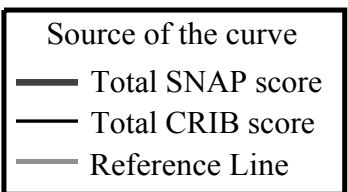

Fig. (6): Receiver Operating Characteristic (ROC) curve for the sensitivity of both of the SNAP II and CRIB scores in predicting mortality in neonates.

Table (5) revealed that both the areas under the ROC curve for SNAP-PE II and CRIB scores were nearly similar. They were $(0.840$ and 0.843$)$ respectively with standard errors of $(0.024,0.022)$ respectively. Accuracy of both scores were equal and both considered good for prediction of neonatal mortality. 
Table (5): Areas under the ROC curve representing the accuracy of both of the SNAP-PE II and CRIB scores in predicting neonatal mortality.

\begin{tabular}{lccccc}
\hline & & & & \multicolumn{2}{c}{$\begin{array}{c}\text { Asymptotic } \\
95 \%\end{array}$} \\
$\begin{array}{l}\text { Test Result } \\
\text { Variable (s) }\end{array}$ & $\begin{array}{c}\text { Area } \\
\text { under } \\
\text { the curve }\end{array}$ & $\begin{array}{c}\text { Std. } \\
\text { Errora }\end{array}$ & $\begin{array}{c}\text { Asymptotic } \\
\text { Sig.b }\end{array}$ & $\begin{array}{c}\text { Confidence } \\
\text { Interval }\end{array}$ \\
\cline { 3 - 6 } & & & & $\begin{array}{c}\text { Lower } \\
\text { Bound }\end{array}$ & $\begin{array}{c}\text { Upper } \\
\text { Bound }\end{array}$ \\
\hline $\begin{array}{l}\text { Total } \\
\text { SNAPPE II } \\
\text { score }\end{array}$ & .840 & .024 & .000 & .793 & .886 \\
$\begin{array}{l}\text { Total CRIB } \\
\text { score }\end{array}$ & .843 & .022 & .000 & .800 & .887 \\
\hline
\end{tabular}

Although the sensitivity of the SNAP-PE II is slightly more than the CRIB; both were considered good; (84.1\% \& 81\%) respectively. Sensitivity of the scores mean their ability to detect those truly liable to die from all neonatal deaths the specificity for both scores were not good enough, $(68.4 \%$ \& $71.1 \%$ ) respectively. Specificity of the scores mean their ability to detect those who were truly not liable to die. Both of the SNAP-PE II and CRIB scores have a low positive predictive value; $(47.3 \%$ $\& 48.6 \%$ ) respectively; which mean their poor ability to predict those who truly died from all neonates with high scores in both scales. According to the results of likelihood ratios $(2.66 \& 0.23)$ and $(2.8 \& 0.27)$ for both of the SNAP-PE II and CRIB scores; they were considered to have a small role and sometimes useful diagnostic tests for predicting neonatal mortality as in Table (6).

Table (6): Validity of the SNAP-PE II and CRIB in prediction of neonatal mortality at the best cut off points for both scores.

\begin{tabular}{rrrrrrr}
\hline & $\begin{array}{l}\text { Sensi- } \\
\text { tivity }\end{array}$ & $\begin{array}{c}\text { Speci- } \\
\text { ficity }\end{array}$ & PVP & PVN & $\begin{array}{c}\text { Like- } \\
\text { lihood } \\
\text { ratio }\end{array}$ & $\begin{array}{c}\text { Like- } \\
\text { ratio }\end{array}$ \\
\hline SNAPPE II & $84.1 \%$ & $68.4 \%$ & $47.3 \%$ & $92.8 \%$ & 2.66 & 0.23 \\
CRIB & $81.0 \%$ & $71.1 \%$ & $48.6 \%$ & $91.7 \%$ & 2.8 & 0.27 \\
\hline
\end{tabular}

$\mathrm{PVP}=$ Predictive value positive. $\mathrm{PVN}=$ Predictive value negative.

\section{Discussion}

In this study, as regards SNAP PE II groups in relation to outcome of the studied patients were proved to be statistically significant as the ( $p$ value $=0.005)$, as the groups increased in severity from group (1) to (5) the neonatal mortality increased $(7.2 \%, 21.5 \%, 48.7 \%, 78.3 \%$ and $85.2 \%)$ respectively.

This is in agreement with a study conducted by Mia et al., [9] a score of 30 and above, Study by Suksham and Anuradha [10] scores of 40 and above, study done by Ucar et al., [11] scores of 33 and above were associated with higher mortality.

In Mia et al., study, done at Soetomo Hospital, Surabaya: the sample size calculation was 80 neonates. During a study period of four months, 80 neonates were evaluated and the necessary investigations for scoring the SNAPPE II were done within 12 hours of admission the mean of SNAPPE II was $26.3 \pm 19.84$ (range 0-81). The SNAPPE II of the non survivals was significantly higher than the survivals ( $42.75 \pm 18.59$ vs $17.4 \pm 14.05)$. They showed that the SNAPPE II value of the non survivals was significantly higher than the survivals. Neonates with SNAPPE II $<10$ have only a mortality of $5 \%$, but SNAPPE II $>60$ was suggestive of poor outcome with mortality $100 \%$ [9].

A similar study was done by Suksham and Anuradha [10], Data collection window was in the first 12 hours after admission to the NICU. A total of 66 babies were admitted in neonatal intensive care unit, NICU during this period and 63 met the inclusion criteria. Mean birth weight was $1382.7 \pm$ 581.3 grams and gestation age was $31.1 \pm 2.9$ weeks. Mortality rate was $11.1 \%$. As the score increased to 40 and above chances of mortality increased, about $(37.5 \%)$, and it was maximum with score of 80 and above, about (100\%) [10]

In the study done by Ucar et al., [11] data from infants admitted between June 2012 and June 2013 to the neonatal intensive care unit with a birth weight less than $1500 \mathrm{gr}$ were collected in a retrospective manner. SNAPPE-II score was calculated for the first $24 \mathrm{~h}$ of each infant. A total of 182 infants (98 males and 84 females) were included in this study. Mean birth weight was $1,134 \pm 264 \mathrm{~g}$. The most notable scores documented for SNAPPEII were 33 for mortality (sensitivity $86.6 \%$, specificity $76,4 \%)$ [11].

A similar study conducted by Kadivar et al., In a prospective study undertaken during the period from 1 st September 2003 to 28 th August 2004, the SNAP-PE II score was applied to all newborns admitted to the NICU of the Children's Medical Center which is a tertiary care unit affiliated to Tehran University of Medical Sciences in Tehran, Iran. They concluded that SNAPPE-II score can be used to predict mortality among the NICU patients. The higher the SNAPPE-II score higher the mortality rate, with SNAP-PE II score more than 19 points mortality was $19.4 \%$. So Kadivar, et al., evaluated SNAP-PE scoring system in 198 newborn and showed SNAP-PE II to be a good 
predictor of mortality among the NICU patients [1].

Similar results were found by Kim et al., [12] in their study to evaluate the clinical usefulness of SNAP, SNAPPE, SNAP II and SNAPPE II. 2021 neonates were evaluated using the previous scores in those who survived more than 24 hours in NICU at Kyunghee University from July 2003 to December 2004. The mean SNAPPE II values were higher in those who died which proved to be statistically significant with mean score for survival group 24.5 compared to 44.0 in death group [12]

In this study, as regard to CRIB groups in relation to outcome of the studied patients were proved to be statistically significant as the ( $p=$ value $=0.005$ ) as the groups increased in severity from group (1) to (4) the neonatal mortality increased $(13.9 \%, 82.9 \%, 90.9 \%$ and $100 \%)$ respectively. And this came in agreement with study was done by Sarquis, et al., [13], score was obtained through a prospective way from 100 newborns with birthweight of $1,500 \mathrm{~g}$ or less or gestational age less than 31 weeks, who were admitted consecutively to the Neonatal Unit of Hospital das Clínicas, Universidade Federal do Paraná. 55 newborns were females and 45 were males, the average birthweight was $1,078 \pm 0.277 \mathrm{~g}$ and gestational age was $29.2 \pm 2.8$ weeks. Twenty-one patients died. The mortality rate in the CRIB groups 1, 2, 3 and 4 was, respectively $6.6 \% ; 46.2 \% ; 87.5 \%$ and $100.0 \%$ [13].

Our study revealed that both areas under the ROC curve for SNAP PE II and CRIB scores were nearly similar. They were $(0.840$ and 0.843$)$ respectively with standard errors of $(0.024,0.022)$ respectively. Accuracy of both are scores were equal and both considered good for prediction of neonatal mortality. And this came in agreement also with Zardo and Procianov [2] who investigated the CRIB, SNAP-PE, and SNAP-PE-II scoring systems The survey included 494 newborns admitted to the neonatal intensive care unit (NICU) of a general hospital in Porto Alegre, southern Brazil, immediately after delivery, between March 1997 and June 1998. They found that no system was statistically superior over another with respect to AUC, The area below the ROC curves ranged from (0.81 to 0.94$)$. There were no statistically significant differences between the areas obtained for all scores evaluated and that the predictive value of the three systems increased with birthweight. The authors concluded that CRIB, SNAP-II, and SNAP-PE-II are useful because they are easily applied if the results are obtained at an early stage or within a short time, within the first $12 \mathrm{~h}$ of admission [2].
Conclusion:

- Both SNAP-PE II and CRIB scores have good sensitivity for predicting neonatal mortality which was slightly higher in SNAP-PE II score.

- Area under the curve of both scores was nearly similar, meaning accuracy of both of them in predicting neonatal mortality.

\section{Recommendations:}

1- Both scores could be routinely applied in all NICUs for predicting neonatal mortality.

2- Similar study including the use of both scoring systems could be applied on different neonatal illness.

3- Wide scale study using different scoring systems for predicting the neonatal outcome.

\section{References}

1- KADIVAR M., SAGHEB S., BAVAFA F., MOGHADAM L. and ESHRATI B.: Neonatalmortality risk assessment in neonatal intensive care unit (NICU). Iran. J. Ped. Dec. Vol., 17 (4): pp. 325-331, 2007.

2- ZARDO M.S. and PROCIANOY R.S.: Comparison between different mortality risk scores in a neonatal intensive care unit. Rev. Saude. Publica, 37 (5): 591-6, 2003.

3- SHIVANNA S.H. and BANUR R.A.: SNAPPE-II (score for neonatal acute physiology with perinatal extensionII ) in predicting mortality and morbidity in NICU. Journa of Clinical and Diagnostic Research, 9 (10): SC10-SC12, 2015.

4- DORLING J.S., FIELD D.J. and MANKTELOW B.: Neonatal disease severityscoring systems. Arch. Dis. Child. Fetal. Neonatal. Ed., 90: F11-F16, 2005.

5- PARRY G., TUCKER J. and TARNOW-MORDI W.: CRIB II: An update of the clinical risk index for babies score. Lancet., 361 (9371): 1789-91, 2003.

6- BALLARD J.L., KHOURY J.C., WEDIG K., WANG L., EILERS-WALSMAN B.L., LIPP R., et al.: New Ballard Score, expanded to include extremely premature infants. J. Pediatrics, 119: 417-423, 1991.

7- RICHARDSON D.K., CORCORAN J.D., ESCOBAR G.J. and LEE S.K.: SNAP-II and SNAPPE-II: simplified newborn illness severity and mortality risk scores. J. Pediatr., 138 (1): 92-100, 2001.

8- International Neonatal Network. The CRIB (clinical risk index for babies) score: A tool for assessing initial neonatal risk and comparing performance of neonatal intensive care units. Lancet., 342: 193-8, 1993.

9- MIA R.A., RISA ETIKA, AGUS HARIANTO, FATIMAH INDARSO and SYLVIATI M.: The use of score for neonatal acute physiology perinatal extention II (SNAPPE II) in predicting neonatal outcome in neonatal intensive care unit, Volume, 45, Paediatrica Indonesiana, 2005. 
10- JAIN S. and BANSAL A.: SNAPPE II score for predicting mortality in a level II neonatal intensive care unit. Dicle. Med. J. Cilt., 36 (4): 333-35, 2009.

11- UCAR S., VARMA M., ETHEMOGLU M.I. and ACAR N.K.: The Effcacy of SNAPPE. II-II in Predicting morbidity and mortality in Extremely Low Birth Weight Infants. Arch. Dis. Child, 99 (Suppl 2): A468, 2014.
12- KIM S.K., MOON Y.H. and BAE C.W.: Scores of SNAP and SNAP variant indices for evaluation of acute severity in newborn infants. J. Korean. Soc. Neonatal., 13 (1): 4046, 2006.

13- SARQUIS A.L., MIYAKI M. and CAT M.N.: The use of CRIB score for predicting neonatal mortality risk. J. Pediatr. (Rio. J.) May-Jun., 78 (3): 225-9, 2002.

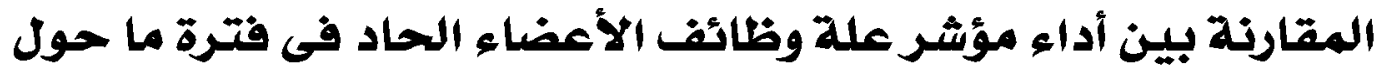

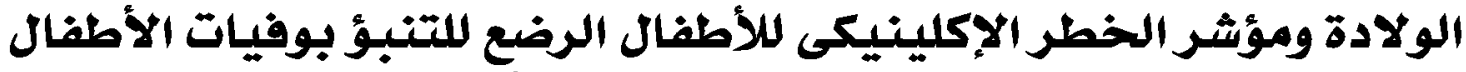

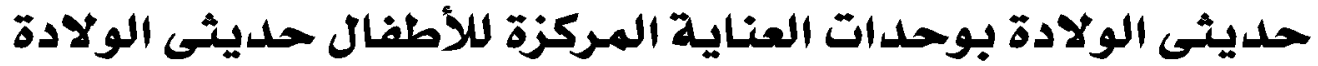 بمستشفيات طنطا الجامعية}

منذ أكثر من عقد وضع نظام مبسط وذلك للتنبؤ بالوفيات فى غضسف Y الساعة من الحجز في وحدة العناية المركزة لحديثى الولادة

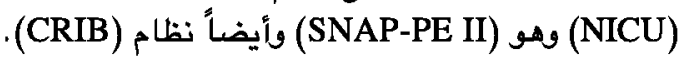

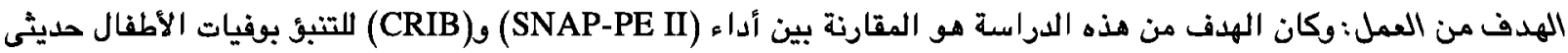

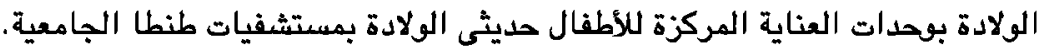

$$
\text { نوع الدراسـة: دراسة مستقبلية. }
$$

المرضى وطرق البحث: تم تنفيذ هذه الدراسة المرتقبة على جميع الأطفال الذين تم حجزهـم بوحدة العناية المركزة للأطفال حديثى

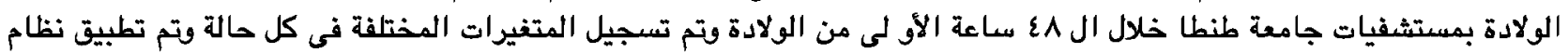
لجميع الحالات وتقسيم مجموع النقاط إلى ه مجموعات. تم تطبيق نظام CRIB أيضاً أساس عدد من النقاط وتونيع الحالات حسب النقاط التى تلقوها أربع مجموعات.

الأستنتاج : إن كلا من SNAP-PE II ولديهما حساسية جيدة للتبؤ بوفيات الأطفال حديثى الولادة والتى كانت أعلى قليلاً فى درجة SNAP-PE II

التوصيات: يمكن تطبيق كلاً من CRIB, SNAP-PE II بشكل روتينى فى جميع وحدات NICU للتنبؤ بوفيات الأطفال حديثى 